\title{
Crashworthiness optimization of aircraft hybrid energy absorbers enclosing honeycomb and foam structures
}

\author{
J. Paz, L. Romera ${ }^{\dagger}$ J. Díaz \\ Structural Mechanics group, School of Civil Engineering, Universidade da Coruña, 15071 A Coruña, Spain
}

This research proposes a new design for a vertical strut used in aircraft fuselages. It consists of a hollow aluminum vertical strut filled with a glass-fiber reinforced polymer honeycomb-shaped structure and polymeric foam. The design is optimized for crashworthiness of aircraft fuselage structures. The variables of the surrogate-based optimization procedures are the thicknesses of the aluminum and polymer, and the cell size and shape. The objective functions for the single-objective optimization are the specific energy absorption and the cost, while the metrics for the multi-objective optimization are the two aforementioned along with the peak force, mass and absorbed energy. By using the polymeric foam, an improvement of $28 \%$ on the specific energy absorption is obtained compared to a component without this reinforcement. Compared to a baseline model, the optimum also reduces the cost by $40 \%$. Three Pareto fronts are obtained, confronting specific energy absorption against peak force and cost, and mass against energy absorbed. When compared to different baseline models, the optimized models show substantial improvement, increasing the specific energy absorption while reducing peak force, mass and costs. An important effect of the cell shape on the model's performance is observed, with the optimum models having pseudo-rectangular cells.

\footnotetext{
*Corresponding author. Tel: +34881016 017; Fax: +34 981167170

${ }^{\dagger}$ Associate Professor

$\doteqdot$ Associate Professor, Senior Member AIAA
} 


\section{Nomenclature}

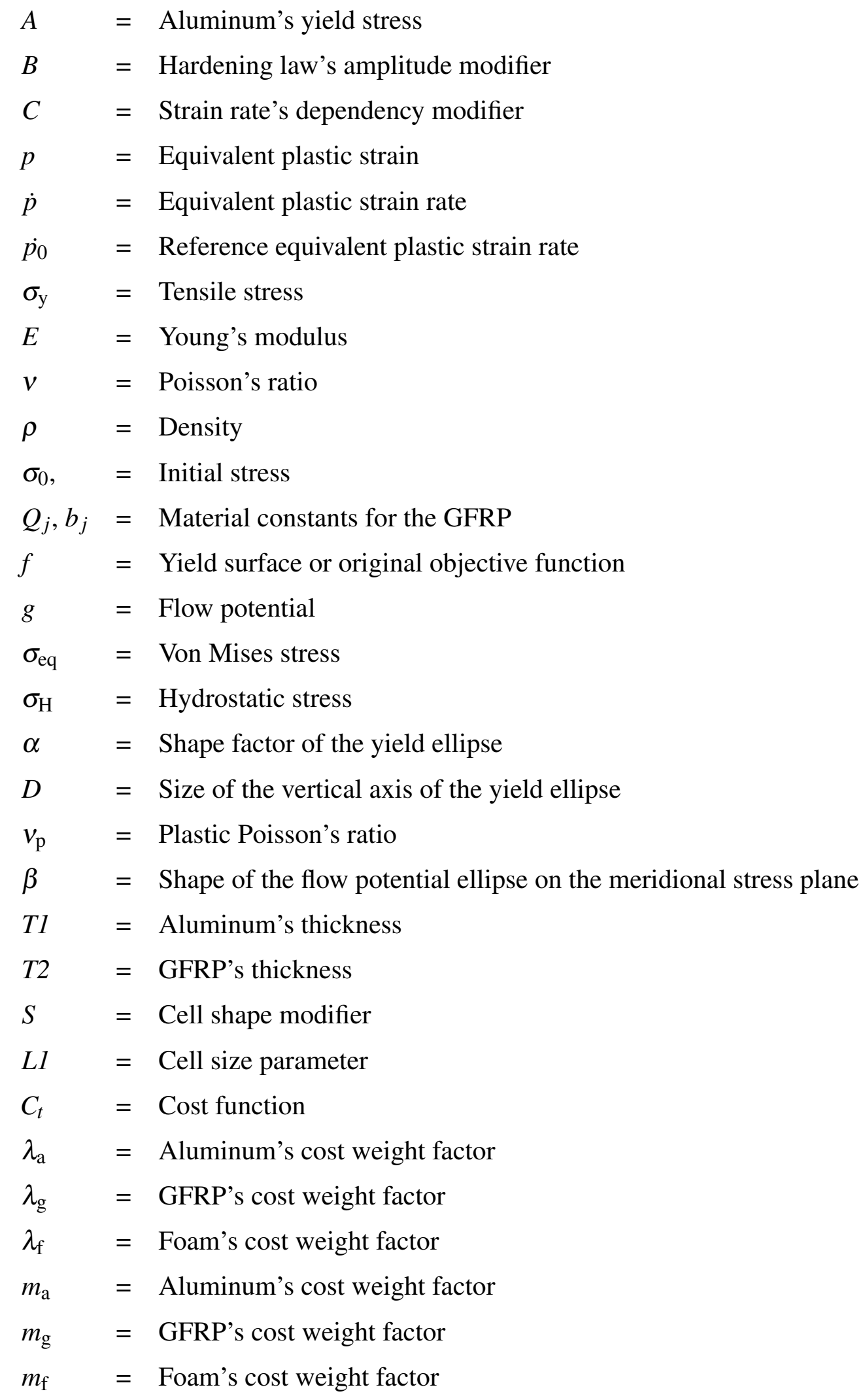


$n=$ Number of sampling points

$\hat{f} \quad=$ Surrogate model

$c_{m}=$ Coefficient for MLS basis functions

$B_{m}=$ MLS basis functions

$M \quad=\quad$ Number of MLS basis functions

$\omega_{h}=$ Point-specific weight for MLS functions

$\Pi_{M}=$ Space of the polynomials used for the MLS

\section{Introduction}

Structural optimization and the structure's energy absorption performance are essential strategies in aircraft design. The usage of these methodologies yields robust and safe craft designs, but also efficient and lightweight, in order to reduce the fuel consumption and increase their payload. The term "crashworthiness" first appeared in the 1970s, and it is defined as a combination of both the structure and the materials' characteristics so that a structure exhibits an outstanding crashresistance and, additionally, exceptional energy-absorption capabilities. Therefore, improving a craft's crashworthiness entails reducing the forces transmitted to the passengers or cargo during a crash, while also considering the efficiency criteria. As an answer to these necessities, diverse standards have been established and enforced by entities such as the Federal Aviation Administration (FAA) or the Joint Airworthiness Requirements (JAR) ${ }^{1}$. Crashworthiness-wise improvement of the landing gear, main fuselage sections, cabin layout and the occupant seat systems has noticeably increased the survival probabilities and lessened passenger injuries after a crash.

Enhancing the fuselage of an aircraft according to the crashworthiness criteria requires either modifying its failure behavior, monitoring the acceleration characteristics, or increasing the structure's energy absorption capabilities. Through different simulations, such as foreign object impacts, explosive blasts, or crash simulations ${ }^{2}$, the aircraft's behavior under impact is obtained. The main deformation area during an impact is located under the the cabin floor ${ }^{3}$. There are three primary structures that manage to absorb most of the energy generated during a $\operatorname{crash}^{2}$ : the sub-cargo area, the aircraft's frame and the vertical struts.

The main area crushed during a potentially survivable impact is the aircraft's sub-cargo region. Many authors are drawing their efforts towards the optimization of this section to improve its performance ${ }^{4 ; 5 ; 6}$. After the sub-floor crushing initiates, the aircraft's circumferential frame is loaded. Techniques such as integrating additional absorbers and plastic hinges, help achieve structural integrity close to the attachments of the vertical struts ${ }^{7}$, increasing noticeably the energy absorbed by the frame.

The vertical struts connecting the passenger cabin floor and the lower part of the frame act 
as vertical support in the middle to large size aircraft range ${ }^{8}$. These vertical tube-like structures are subjected to axially-dominated compressive loads during a crash. Hence, it is vital to ensure that they absorb the required amount of energy while keeping the necessary living space after the impact. Their effect on the crashworthiness of the aircraft is greatly dependent on their structural stiffness ${ }^{9 ; 10}$ : while a rigid strut helps the lower part of the fuselage dissipate more energy, the cabin floor would endure more if flexible struts are fitted.

The study of the response under the axial loads of tubular structures similar to these struts first started in the 1960s, with the work from Alexander ${ }^{11}$. This was later on complemented by other authors ${ }^{12 ; 13}$, experimenting with various tube shapes and load cases applied.

For the efficient implementation of the struts in the fuselage, various simulations with finite element modeling have been performed. Their configuration and position ${ }^{14}$, the implementation of triggers ${ }^{15}$, the crushing behavior ${ }^{16}$, or the strut's response implemented in a whole fuselage section ${ }^{17}$ are some of the tests in the scope of investigators.

Furthermore, the struts can be enhanced by adding an inner material that complements the strut's failure behavior. This inner reinforcement can vary in shape, size and material, thus obtaining a wide range of plausible configurations and, therefore, strut responses. This inner composite materials act a core bracing effect, constraining the ductile collapse process of the metal and enhancing its response ${ }^{18}$.

The shape of the inner reinforcement can range from tight-compact to honeycomb-like structures, including complex geometries or cores of laminates. While all of them improve the performance of the component, the honeycomb, whether it is a regular hexagon or a modified shape, has proved to be excellent in bettering the response of these structures ${ }^{19 ; 20 ; 21}$. Moreover, tight-compact structures made from cork and foam also give a very stable and progressive response ${ }^{22 ; 23}$. Combining a glass- or carbon-fiber reinforced polymer (GFRP/CFRP) structure with foam presents itself as an option, obtaining the best of all three materials: the metal, the polymer and the foam. Costas et al. ${ }^{24}$ combine a circular metallic tube, a GFRP matrix and polymeric foam triangles in one component. Thus, and despite never being considered so far, embedding foam inside a honeycomb inner reinforcement also appears to be an interesting option.

This investigation is based on finite element modeling, analysis, and size and shape optimization of a standard thin-walled aluminum strut filled with a GFRP honeycomb structure embedded in polymeric foam. The large computational resources required claim for the use of surrogate models, as they have proved very effective when relating the impact responses to the design variables in highly non-linear optimization problems ${ }^{25}$. After sampling the workspace, a surrogate function is fitted, so it can later on save significant computational time during the single- and multi-objective optimization processes. The four variables chosen for the optimization are the wall thickness of the tube and the honeycomb's cell shape, size and wall thickness. On the other hand, the functions used to validate the strut's response cover different criteria: effectiveness as an energy-absorption 
device, passenger and cargo safety, and the industrial costs. After this optimization process, the resulting design variables' combination is tested on a finite element model to prove the optimization's efficacy. Finally, the piece is compared to the original strut without foam to quantify the improvement of the optimized model.

\section{Component description}

For this research, a novel vertical strut design is proposed, aiming for effective and efficient absorption of the energy involved in aircraft fuselage crashes. The component is a combination of three different parts: an outer metallic tube and two inner reinforcements made from glass-fiberreinforced polyamide and polymeric foam.

\section{II.A. Materials and constitutive equations}

The three parts composing the component are made from three different materials. The outer tube's metal is an AA7075-T651 aluminum alloy, the honeycomb inner reinforcement is made with the glass-fiber-reinforced polyamide Ultramid A3WG10 BK00564 from BASF, while the polymeric foam filling the honeycomb cells is ArmaFORM PET/W AC 135 from Armacell.

The aluminum has been modeled according to the modified Johnson-Cook strain-rate sensitive model $^{26 ; 27}$ disregarding any effect the temperature may cause on the material. Consequently, the constitutive equation for the aluminum is defined as

$$
\sigma_{\mathrm{y}}=\left(A+B p^{b}\right)\left(1+\frac{\dot{p}}{\dot{p_{0}}}\right)^{C}
$$

where $A$ is the material's yield stress, $B$ is the hardening law's amplitude modifier, $p$ is the equivalent plastic strain, $\frac{\dot{p}}{\dot{p_{0}}}$ is the dimensionless equivalent plastic strain rate, and $C$ is the strain-rate's dependency modifier. All material and model parameter values, taken from the work of Børvik et al. ${ }^{28}$, are detailed in table 1.

\begin{tabular}{cccccccc}
\hline$E$ & $v$ & $\rho$ & $A$ & $B$ & $n$ & $C$ & $\dot{p_{0}}$ \\
\hline $70 \mathrm{GPa}$ & 0.3 & $27.7 \mathrm{kN} / \mathrm{m}^{3}$ & $520 \mathrm{MPa}$ & $477 \mathrm{MPa}$ & 0.52 & 0.001 & $0.0005 \mathrm{~s}^{-1}$ \\
\hline
\end{tabular}

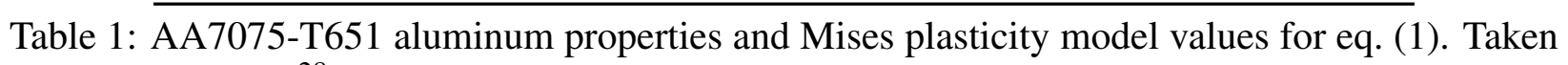
from Børvik et al. ${ }^{28}$.

The GFRP's properties have been extracted from the manufacturer's data sheets ${ }^{29}$ as well as from the data recorded from tensile tests ${ }^{30}$. The plasticity model used is adjusted to the polymer's visco-elastic behavior, limiting the maximum true strain at $2.38 \%$, where the material fails. The 
parameters for the eq. (2) that models the GFRP behavior are shown in table 2.

$$
\sigma_{\mathrm{y}}=\sigma_{0}+\left[\sum_{j=1}^{k} Q_{j}\left(1-e^{-b_{j} p}\right)\right]
$$

where $Q_{j}, b_{j}$ and $\sigma_{0}$ are material constants, and $k$ is the number of terms used to approximate the material's response. For this material, $k=2$. Both the aluminum and the GFRP models have been more thoroughly described in Paz et al. ${ }^{30}$.

\begin{tabular}{cccccccc}
\hline$E$ & $v$ & $\rho$ & $\sigma_{0}$ & $Q_{1}$ & $Q_{2}$ & $b_{1}$ & $b_{2}$ \\
\hline $10.16 \mathrm{GPa}$ & 0.4 & $15.5 \mathrm{kN} / \mathrm{m}^{3}$ & $25 \mathrm{MPa}$ & $124.86 \mathrm{MPa}$ & $44.46 \mathrm{MPa}$ & 315.89 & 5748.46 \\
\hline
\end{tabular}

Table 2: Material properties of Ultramid A3WG10 BK00564.

As for the foam, various material tests were performed by Costas et al. ${ }^{24}$ in order to obtain its behavior under compressive loads. Despite being an orthotropic material, it was considered that the foam was loaded parallel to the extrusion (or strong) direction. The mechanical properties used to model this material have been detailed in table 3. An isotropic foam hardening model proposed by Deshpande and Fleck ${ }^{31}$ for metallic foams was used to model the foam's behavior. The yield surface $f$, which includes pressure dependency, is modeled by a Mises circle in the deviatoric stress plane and an ellipse centered in the meridional stress plane as

$$
f=\sqrt{\sigma_{\mathrm{eq}}^{2}+\alpha^{2} \sigma_{\mathrm{H}}^{2}}-D=0,
$$

with $\sigma_{\text {eq }}$ being the von Mises stress, $\sigma_{\mathrm{H}}$ the hydrostatic stress, $\alpha$ the shape factor of the yield ellipse that defines the relative magnitude of the axis, and $D$ the size of the vertical axis of the yield ellipse.

Furthermore, a flow potential $g$ was used to represent non-associated flow as

$$
g=\sqrt{\sigma_{\mathrm{eq}}^{2}+\beta^{2} \sigma_{\mathrm{H}}^{2}}=0
$$

where $\beta$ represents the shape of the flow potential ellipse on the meridional stress plane, dependent on the plastic Poisson's ratio $v_{\mathrm{p}}$. Figure 1 shows the crushable foam constitutive model with isotropic hardening along the meridional plane.

Moreover, the true stress versus true strain foam curve is depicted in fig. 2, showing the comparison of both the numerical and the analytical behavior of the material. 


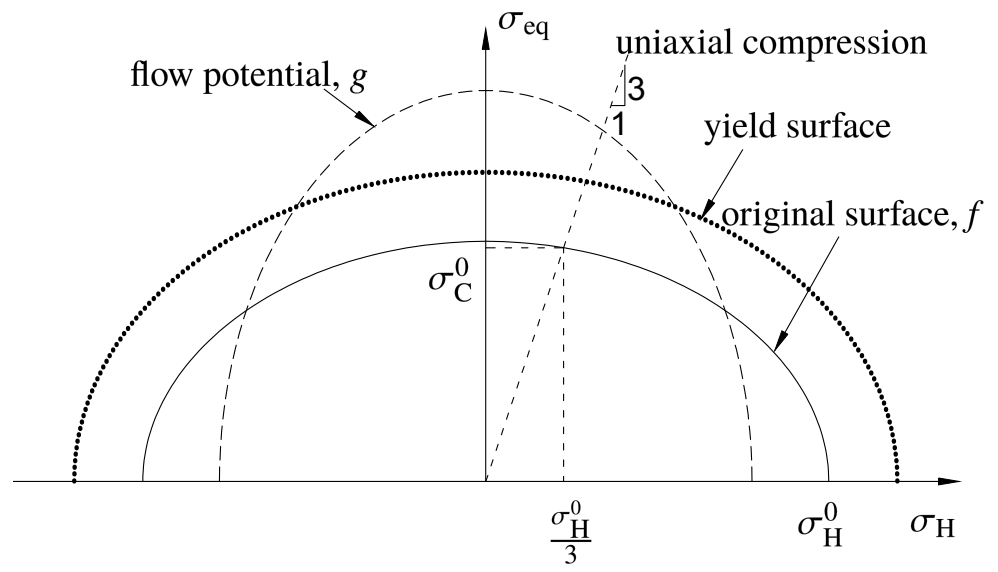

Figure 1: Yield surface and flow potential in the meridional plane for the crushable foam model with isotropic hardening.

\begin{tabular}{cccccc}
\hline$E$ & $v$ & $\rho$ & $\alpha$ & $\beta$ & $v_{\mathrm{p}}$ \\
\hline $59.006 \mathrm{MPa}$ & 0.1 & $1.35 \mathrm{kN} / \mathrm{m}^{3}$ & 0.729 & 1.7754 & 0.1109181 \\
\hline
\end{tabular}

Table 3: Material properties of ArmaFORM PET/W AC 135.

\section{II.B. Design variables and objective functions}

The component studied is geometrically defined by three design parameters and four design variables. A $500 \mathrm{~mm}$ hollow square tube is proposed, with a $150 \mathrm{~mm}$ edge. Both the honeycomb and foam reinforcements measure $50 \mathrm{~mm}$ less than the outer tube in order to reduce the combined peak force during the crushing process. The design variables include the thickness of the aluminum (T1) and GFRP (T2), as well as the cell's shape modifier (S) and size (L1), as shown in figs. 3 and 4. The cell shape modifier can vary the cell from a regular hexagon $(S=0)$ to an hourglass shape ( $S$ $=0.75)$, with the intermediate rectangular shape $(S=0.5)$. It is defined as

$$
S=\frac{L 2}{L 1},
$$

The initial values and bounds of all design variables, as well as the description of which part they belong to, are listed in table 4.

The foam shape adapts to that of the void left by the honeycomb cells. However, a onemillimeter gap is left between the honeycomb and foam opposing surfaces in order to facilitate the convergence of the numerical model as the foam has a void to slightly expand. This has no significant impact on the component's performance and, by doing so, the assembly of the component would be less demanding, since this gap eases the insertion of the foam into the cells.

Another design aspect that can be perceived in fig. 4 is that the gaps between the honeycomb structure and the tube are empty when the full size foam structure cannot fit. This facilitates the 


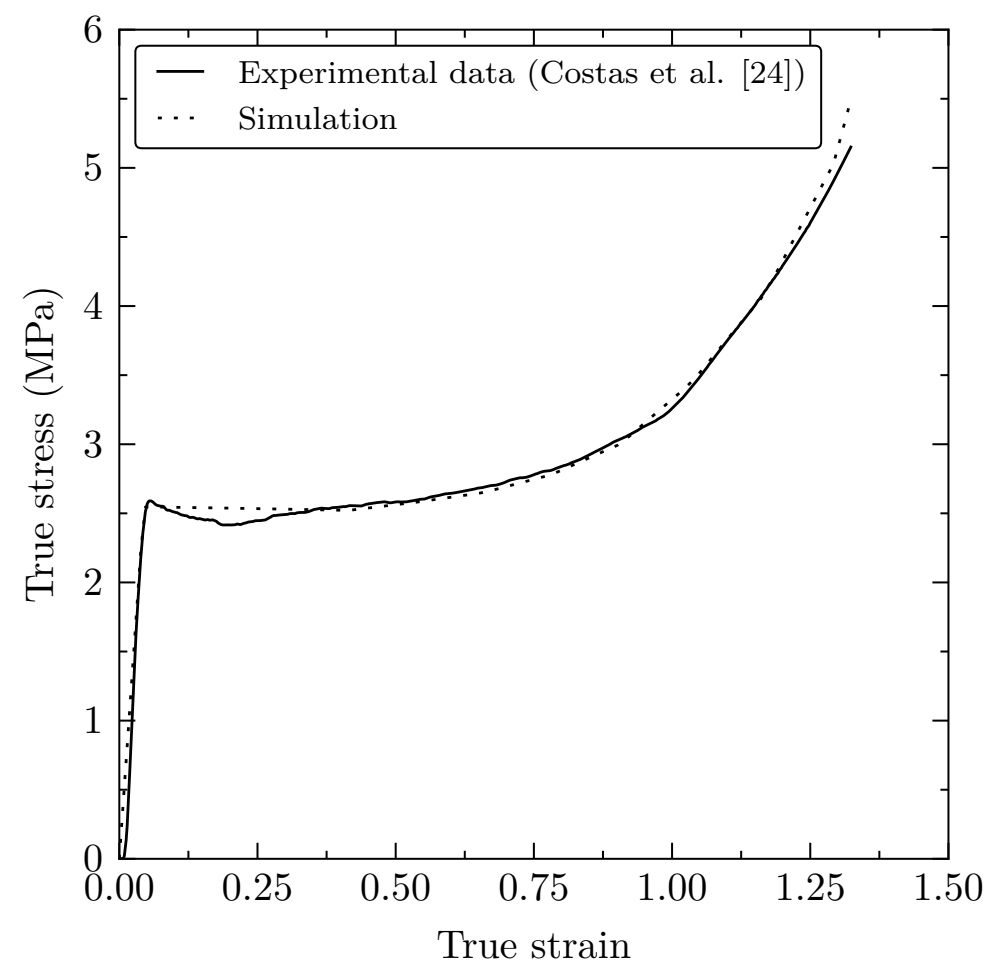

Figure 2: Stress-strain curve of the ArmaFORM PET/W AC 135.

modeling process and assembly of the component, in view of the fact that custom-cut pieces would increase the cost of the design and building processes.

A total number of five objective functions have been considered, three of them being simple metrics and the other two a combination of them. The first three functions are the energy absorbed $\left(E_{\mathrm{a}}\right)$, the component's mass $(m)$ and the peak crushing force $\left(P_{\text {peak }}\right)$. Furthermore, the specific energy absorption (SEA), defined as the energy absorbed per mass unit, and a cost function $\left(C_{t}\right)$ have been computed. This last function has been approximated by multiplying each part's mass by different estimated weight factors that consider the price of the materials. Hence, the component's cost is approximated according to:

\begin{tabular}{lcrrr}
\hline & & \multicolumn{2}{c}{ Bounds } & \\
\cline { 3 - 4 } Part & Variable & Lower & Upper & Initial Value \\
\hline Tube & T1 & 1.00 & 2.50 & 1.50 \\
\hline \multirow{3}{*}{ Honeycomb } & T2 & 1.00 & 3.00 & 1.50 \\
& L1 & 9.00 & 18.00 & 10.00 \\
& $\mathrm{~S}$ & 0.00 & 0.75 & 0.00 \\
\hline
\end{tabular}

Table 4: Bounds and initial values of design variables. All dimensions in millimeters. 


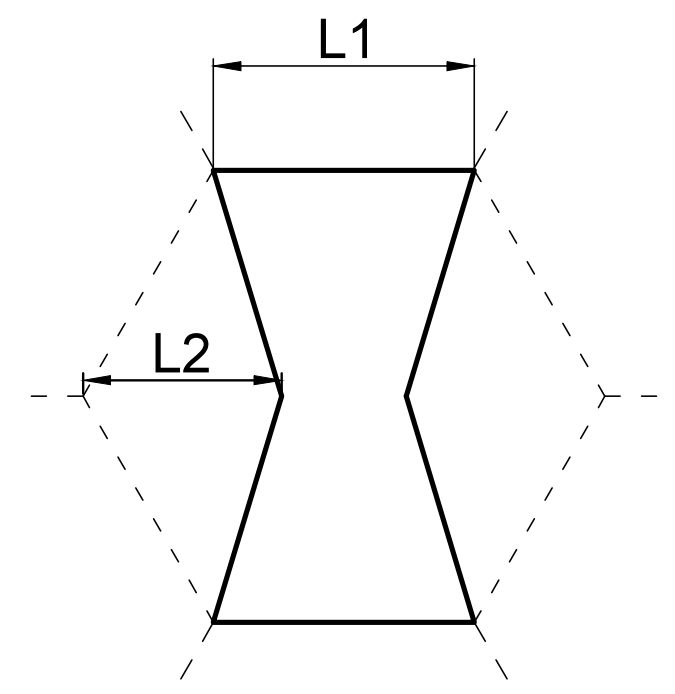

Figure 3: Cell's size and shape modifiers.

$$
C_{t}=\lambda_{\mathrm{a}} m_{\mathrm{a}}+\lambda_{\mathrm{g}} m_{\mathrm{g}}+\lambda_{\mathrm{f}} m_{\mathrm{f}}
$$

where $\lambda_{\mathrm{a}}, \lambda_{\mathrm{g}}$ and $\lambda_{\mathrm{f}}$ are the weight factors for, respectively, the aluminum, GFRP and foam; and $m_{\mathrm{a}}$, $m_{\mathrm{g}}$ and $m_{\mathrm{f}}$ are their masses. Four weight combinations have been used (table 5), all of them with a fixed $\lambda_{\mathrm{a}}=1.0$ and variable $\lambda_{\mathrm{g}}$ and $\lambda_{\mathrm{f}}$. This variation in the weights is implemented to consider the cost fluctuation in the manufacturing process. For the first configuration, SC1, all weights are 1.0, so that the $C_{t}$ (and the optimization of this function) is identical as the mass of the component.

\begin{tabular}{lrrr}
\hline Configuration & $\lambda_{\mathrm{a}}$ & $\lambda_{\mathrm{g}}$ & $\lambda_{\mathrm{f}}$ \\
\hline $\mathrm{SC} 1$ & 1.0 & 1.0 & 1.0 \\
$\mathrm{SC} 2$ & 1.0 & 0.85 & 0.85 \\
$\mathrm{SC} 3$ & 1.0 & 1.15 & 0.85 \\
$\mathrm{SC} 4$ & 1.0 & 0.85 & 1.15 \\
\hline
\end{tabular}

Table 5: Different weight factors for the cost function from eq. (6).

With these five objective functions, the most significant aspects for the construction of a viable strut are considered: its effectiveness as an energy-absorption device (through the measurement of the $E_{\mathrm{a}}$ and $S E A$ ), the maximum deceleration transmitted to the surrounding structure (by monitoring $\left.P_{\text {peak }}\right)$, and its $\operatorname{cost}\left(C_{t}\right)$. 


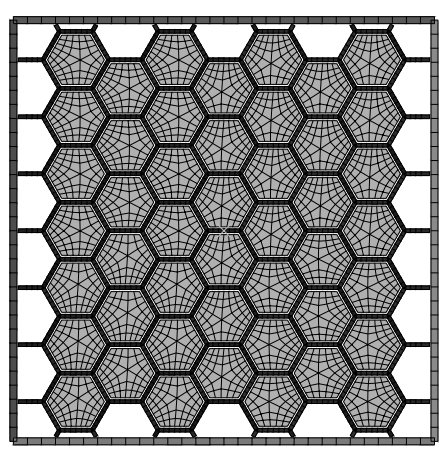

(a) $\mathrm{S}=0$

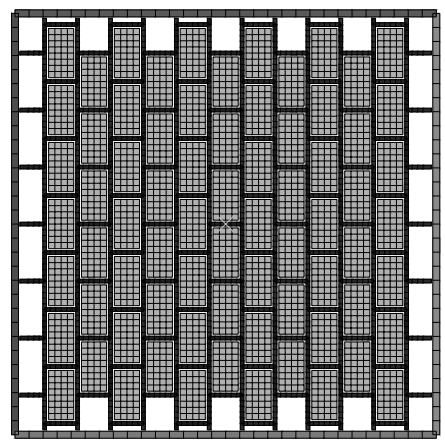

(c) $\mathrm{S}=0.5$

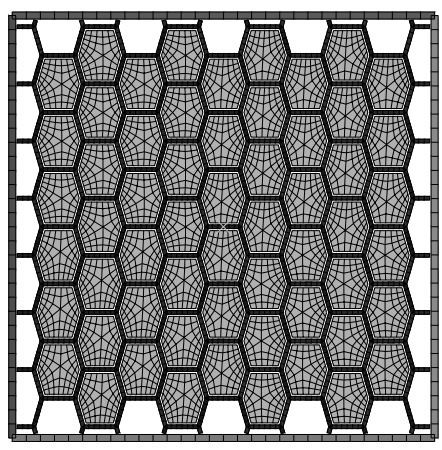

(b) $\mathrm{S}=0.25$

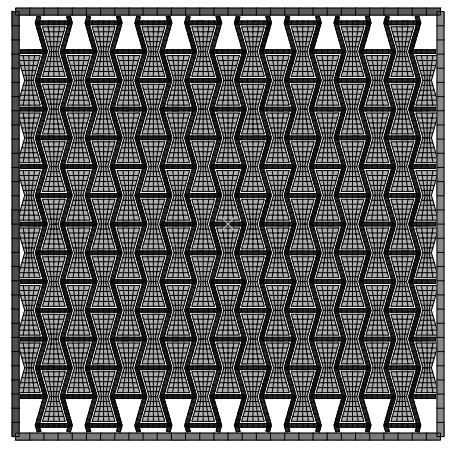

(d) $\mathrm{S}=0.75$

Figure 4: Significant cell shapes. 


\section{Surrogate model and optimization}

Given the characteristics of the model and the optimization process sought with this research, the use of surrogate-based methods is chosen. By drawing the efforts towards the building of a robust surrogate model, all further calculations, such as the single- and multi-objective optimization proposed are significantly less time-consuming.

The $n$ points selected for the sampling have been chosen according to the Latin Hypercube Sampling (LHS) strategy ${ }^{32 ; 33}$.

The surrogate model is built with the $n$ points from the sampling. For such a task, the Moving Least Squares (MLS) technique is used, since it yielded reliable models with little error in the process. With this approximation, the surrogate model is adjusted with polynomials according to the following formula:

$$
\hat{f}(\boldsymbol{x})=\sum_{m=1}^{M} c_{m} B_{m}(\boldsymbol{x}),
$$

where $B_{m}$ are the polynomial basis functions, $c_{m}$ are the coefficients of the functions, $M$ is the number of functions and $\boldsymbol{x}$ is the design variables' vector. To adjust the $c_{m}$ coefficients, the sum of the squared residuals is minimized. Each residual is also assigned a point-specific weight $\omega_{h}$ that considers its relevance to the overall model as follows:

$$
\min _{\hat{f} \varepsilon \Pi_{M}} \sum_{h=1}^{n} \omega_{h}\left(\left\|\hat{f}\left(\boldsymbol{x}_{h}\right)-f\left(\boldsymbol{x}_{h}\right)\right\|\right),
$$

where $\Pi_{M}$ is the space of the polynomials used. This method and its working principles are more thoroughly explained by Nealen ${ }^{34}$.

Once the surrogate model is obtained, it is optimized using genetic algorithms, given the noisy nature of the model ${ }^{35}$. First, the single-objective optimization is performed, followed by different multi-objective optimizations, which yield the best model - or set of models - attending to the different objective functions.

Two genetic algorithms have been selected for the optimization task: a single-objective genetic algorithm (SOGA) and a multi-objective genetic algorithm (MOGA), both of them from the JEGA library ${ }^{36}$. While the results obtained from the SOGA are one single point, the MOGA provides a set of points - the Pareto frontier - which represents a trade-off between the functions considered. The parameters chosen for the genetic algorithms which yielded the best results are detailed in table 6. 


\begin{tabular}{lr}
\hline Parameter & Value \\
\hline Population size & 750 \\
Offset normal mutation rate & 0.8 \\
Two-point crossover probability & 0.8 \\
Elitism & 100 \\
Maximum allowed individuals & $10^{5}$ \\
\hline
\end{tabular}

Table 6: Configuration parameters for the JEGA library optimization algorithms.

\section{III.A. Analysis settings}

The model has been parametrized and implemented in a software for FEA. Concerning the mesh, different sizes were used throughout the model, according to the material's behavior and the part's shape. A mesh sensitivity analysis (table 7) showed that the outer tube and the honeycomb should be modeled with quadrilateral shell elements with reduced integration, with edges approximately four millimeters long. This mesh size ensures a stable collapse of the tube, with the same number of folds and similar absorbed energy obtained with finer meshes. The usage of solid elements for this parts is disregarded due to the large number of elements required for the analysis and the consequently high computational cost. For the foam, solid eight-node elements with reduced integration were used, with an edge of four millimeters, and distortion and enhanced hourglass controls to ensure convergence. A three-dimensional cut of the baseline meshed model is presented in fig. 5.

\begin{tabular}{cc}
\hline Mesh size $(\mathrm{mm})$ & Energy absorbed $(\mathrm{kJ})$ \\
\hline 16 & 133.833 \\
13 & 127.618 \\
10 & 119.206 \\
8 & 117.674 \\
6 & 112.036 \\
5 & 108.948 \\
4 & 106.688 \\
3 & 105.843 \\
2 & 105.830 \\
\hline
\end{tabular}

Table 7: Energy absorbed values for different mesh sizes.

A two-millimeter triggering is applied to the upper edges of the aluminum tube to guarantee a regular collapse mode of the model, reduce the initial peak force, and aid with the convergence of 
the model. The impact velocity chosen for the simulation is $15 \mathrm{~m} / \mathrm{s}$, with the model being crushed 400 millimeters ( $80 \%$ of the tube's length).

Another model is built without the foam filling the honeycomb cells. All the boundary conditions, design variables' range and analysis settings mimic those of the first component, so as to be able to accurately compare the results from both models.

Both samplings consist on $n=600$ data points, enough to obtain reasonably low values for the $R M S E$ metric and values in the vicinity of 1 for the $R^{2}$. Each sample has been run with the explicit module of the Abaqus 6.14 FEA package ${ }^{37}$. The software allows two different parallelization schemes: domain or loop parallelization. Preliminary tests showed that the domain parallelization with eight processors per sample resulted in competent computing times for the analysis, with simulations needing approximately six hours to complete. The construction of the surrogate model and the surrogate-based optimization procedures have been computed with the DAKOTA 6.1.0 framework $^{38}$. Both the Abaqus and the DAKOTA softwares are run on a high performance computing (HPC) cluster, with a theoretical peak performance of 7.6 TFLOPS.

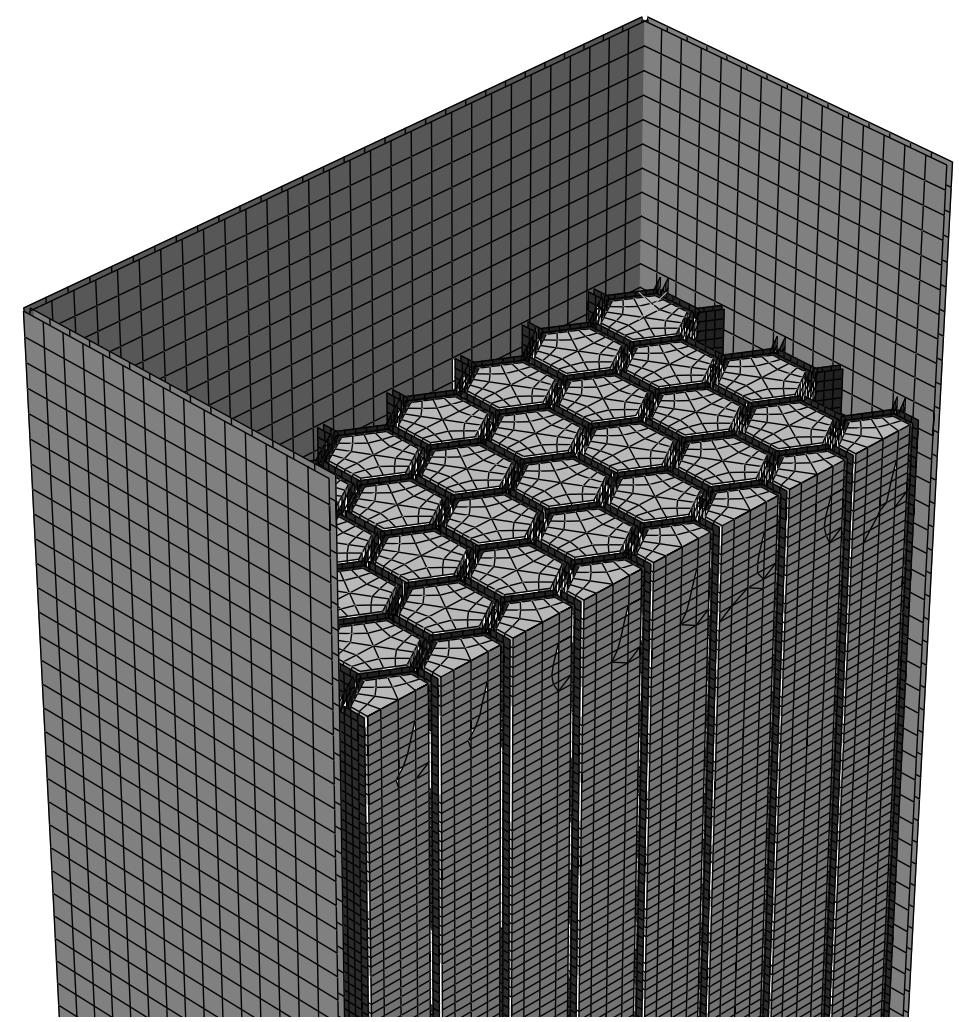

Figure 5: Three-dimensional cut of the baseline model.

\section{III.B. Surrogate models fitness}

In order to measure the accuracy of the surrogate models, two metrics have been evaluated: the $R^{2}$ and RMSE. The results shown in table 8 indicate the fitness of the model, with high $R^{2}$ values and 
a significantly low RMSE. However, to check the consistency of the surrogate model, all the values obtained from the optimization will be calculated to validate the results obtained.

\begin{tabular}{llcl}
\hline Method & Metric & $R^{2}$ & \multicolumn{1}{c}{$R M S E$} \\
\hline \multirow{4}{*}{ MLS } & $m$ & 0.9988 & $0.0259 \mathrm{~kg}$ \\
& $E_{\text {a }}$ & 0.9782 & $1.5493 \mathrm{~kJ}$ \\
& $P_{\text {peak }}$ & 0.9896 & $7.9091 \mathrm{kN}$ \\
& $S E A$ & 0.8881 & $0.2373 \mathrm{~kJ} / \mathrm{kg}$ \\
& $C_{t}$ & 0.9995 & 0.0230 \\
\hline
\end{tabular}

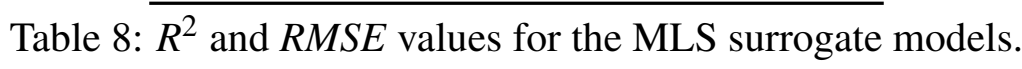

\section{Results and discussion}

\section{IV.A. Single-objective optimization}

\section{IV.A.1. SEA optimization}

In this case, the baseline model is optimized using the single-objective algorithm. Since the SEA includes both the energy absorbed by the component and its mass, it was chosen as the objective function. The first optimization performed yielded an optimum with a $26 \%$ higher specific energy absorption compared to the baseline model (table 9), a noticeable increase in the aluminum's thickness and a cell shape near the rectangle (fig. 6). This shape is the most efficient for the component proposed, since it yields the lowest GFRP mass and, therefore, allows for higher foam mass to fill the component. However, the peak force is also increased by $25 \%$ (fig. 7) due to the thicker materials. In order to solve this problem, another $S E A$ optimization is sought, but this time the value of $P_{\text {peak }}$ is limited to $420 \mathrm{kN}$, which is lower than the peak force of the baseline model. The result is still an optimum with a SEA value $22 \%$ higher than that of the baseline model, but complying with the maximum crushing force limit. In this model, the cell size and the fiber's thickness are reduced, with a cell shape between the regular hexagon and the rectangle.

Furthermore, two SEA optimizations are performed on modified components. For the model with no foam, the optimum has a SEA value slightly lower than the baseline model with the foam, and $28 \%$ lower than the unconstrained optimum, thus proving the effectiveness of adding foam to the proposed component. For the model with no honeycomb and a single foam block inside, its $S E A$ is the highest among the results obtained. However, the energy absorbed is less than $75 \mathrm{~kJ}$, and without any changes in the tube's thickness boundaries, this value cannot be surpassed, thus yielding efficient components but with no room for improvement through optimization techniques. 


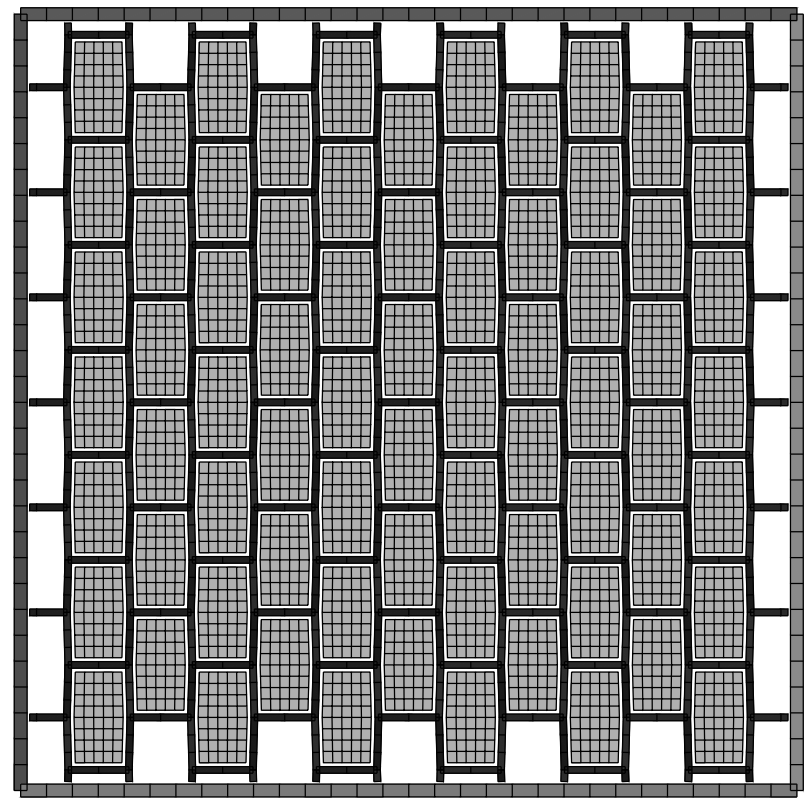

Figure 6: Top view of the optimum model for the single-objective SEA unconstrained optimization.

\begin{tabular}{|c|c|c|c|c|c|c|c|}
\hline \multirow[t]{2}{*}{ Model } & \multicolumn{4}{|c|}{$\begin{array}{c}\text { Design } \\
\text { variables }(\mathrm{mm})\end{array}$} & \multirow{2}{*}{$\begin{array}{l}\text { Objective } \\
\text { function } \\
\frac{S E A(\mathrm{~kJ})}{}\end{array}$} & \multirow{2}{*}{$\frac{\text { Constraint }}{P_{\text {peak }}(\mathrm{kN})}$} & \multirow{2}{*}{$\frac{\text { Metric }}{E_{\mathrm{a}}(\mathrm{kJ})}$} \\
\hline & L1 & $\mathrm{T} 1$ & $\mathrm{~T} 2$ & $\mathrm{~S}$ & & & \\
\hline Baseline & 10.00 & 1.50 & 1.50 & 0.00 & 19.04 & 425.97 & 87.60 \\
\hline Unconstrained & 11.72 & 2.47 & 1.28 & 0.48 & 24.04 & 532.25 & 125.99 \\
\hline Constrained & 9.63 & 2.49 & 1.01 & 0.20 & 23.17 & 418.78 & 109.44 \\
\hline No foam & 14.73 & 2.50 & 1.10 & 0.28 & 18.76 & 424.30 & 64.93 \\
\hline Only foam & & 2.50 & & & 27.82 & 377.50 & 74.36 \\
\hline
\end{tabular}

Table 9: Single-objective $S E A$ optimization results.

\section{IV.A.2. Cost optimization}

Another single-objective optimization is carried out, only this time the objective function is the cost of the component. The four configurations from table 5 were used. The optimization procedure comprised the minimization of $C_{t}$, while complying with two boundary conditions:

$$
\begin{aligned}
P_{\text {peak }} & \in[254.00,256.00] \\
S E A & \in[19.50,20.00]
\end{aligned}
$$

The optima obtained are compared to the baseline model in table 10. It can be seen that the 


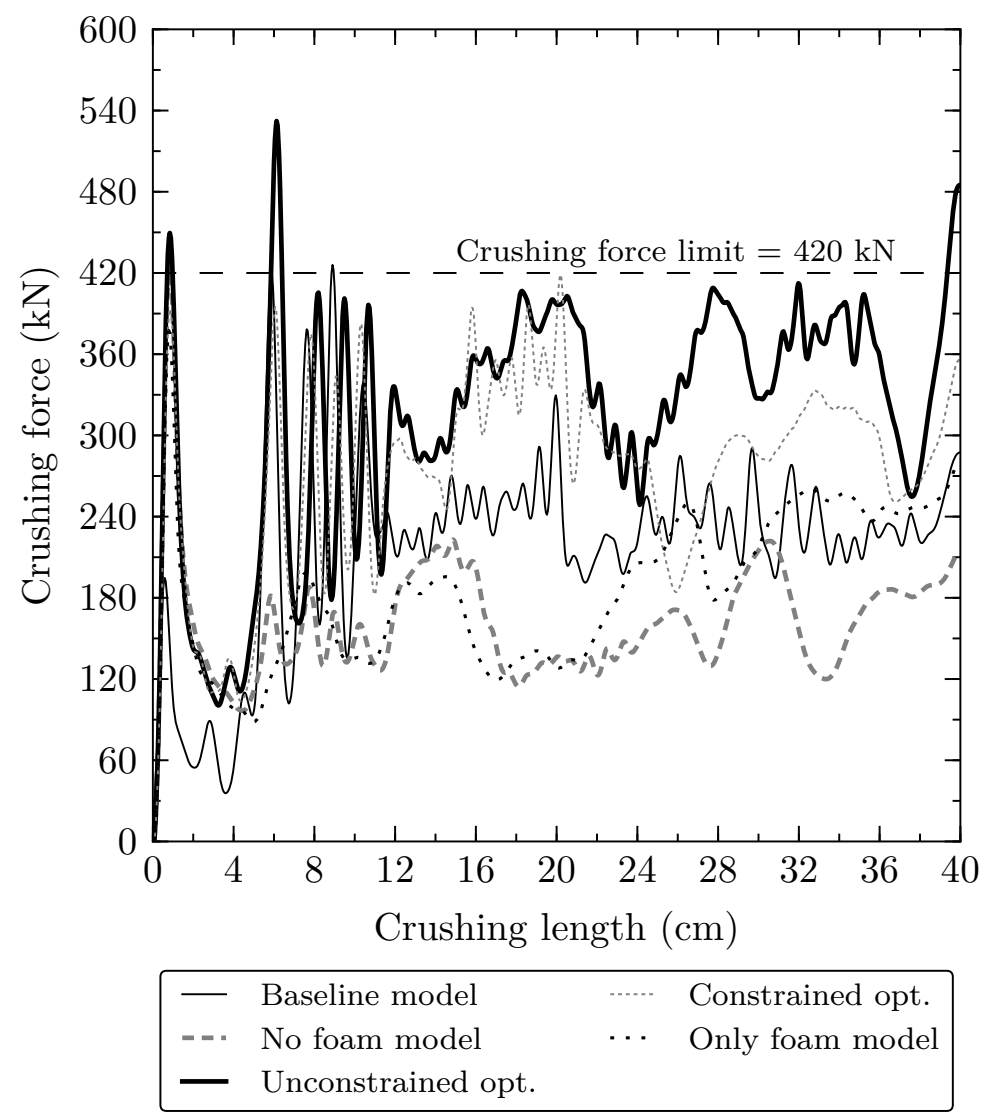

Figure 7: Baseline component compared to the model without foam, the model with only a foam filling, and the constrained and unconstrained optima.

specific energy absorption of all models is similar, and even with a peak force constraint $40 \%$ lower than the baseline model, the hypothetical cost of the component is lowered up to $40 \%$. This is achieved by increasing the cell size and reducing the GFRP thickness to the lowest value allowed, as well as minor cell shape variations for all four optimized combinations.

Finally, the $C_{t}$ function evolution for the SC4 case along the genetic algorithm is monitored. As seen in fig. 8, during the first 500 function evaluations, the values for $C_{t}$ are rather disperse. However, after that point, they stabilize and range between the values of 2 and 5, with a thicker point-cloud around the 2.90 value, which, as seen in table 10 , is the optimum.

\section{IV.B. Multi-objective optimization}

Three different multi-objective optimizations have been executed, all of them with two objective functions: $m-E_{\mathrm{a}}, S E A-P_{\text {peak }}$ and $S E A-C_{t}$. 


\begin{tabular}{|c|c|c|c|c|c|c|c|}
\hline \multirow[t]{2}{*}{ Model } & \multicolumn{4}{|c|}{$\begin{array}{c}\text { Design } \\
\text { variables }(\mathrm{mm})\end{array}$} & \multirow{2}{*}{$\begin{array}{c}\text { Objective } \\
\text { function } \\
C_{t}\end{array}$} & \multicolumn{2}{|c|}{ Constraint } \\
\hline & L1 & $\mathrm{T} 1$ & $\mathrm{~T} 2$ & $\mathrm{~S}$ & & $S E A(\mathrm{~kJ})$ & $P_{\text {peak }}(\mathrm{kN})$ \\
\hline Baseline & 10.00 & 1.50 & 1.50 & 0.00 & 4.37 & 19.04 & 425.97 \\
\hline $\mathrm{SC} 1 \mathrm{opt}$ & 17.71 & 1.88 & 1.00 & 0.26 & 3.31 & 19.69 & 254.77 \\
\hline $\mathrm{SC} 2 \mathrm{opt}$ & 16.85 & 1.86 & 1.00 & 0.24 & 2.62 & 19.59 & 255.12 \\
\hline SC3 opt & 16.68 & 1.82 & 1.00 & 0.14 & 2.97 & 19.53 & 255.07 \\
\hline SC4 opt & 16.76 & 1.85 & 1.00 & 0.15 & 2.90 & 19.56 & 255.07 \\
\hline
\end{tabular}

Table 10: Single-objective $C_{t}$ optimization results.

\section{IV.B.1. Mass - Ea optimization}

The Pareto frontier obtained is presented in fig. 9. Its behavior is tabulated in table 11, where the SEA is also presented. As the mass and energy absorbed increase, the cell size gradually decreases, since a smaller cell size enlarges the mass of the GFRP in the component, and, consequently, the energy absorbed. Moreover, the aluminum and the GFRP thicken. The aluminum thickness is on the upper boundary for components with a mass between 4.5 and $12 \mathrm{~kg}$, thus showing its significant influence and behavior when seeking high $S E A$ values. The cell shape swifts from the regular hexagon until it ultimately reaches the hourglass shape, since this configuration increases the GFRP mass of the model, and therefore, the energy the component absorbs. However, the hourglass shape is not as efficient as the rectangular configuration, as revealed with the slight decrease of the $S E A$. Concerning the $S E A$ indicator, its value increases from $15 \mathrm{~kJ} / \mathrm{kg}$ until reaching a maximum of $24 \mathrm{~kJ} / \mathrm{kg}$ for components with a mass in the vicinity of five kilograms. After that, it progressively decreases again to values near $20 \mathrm{~kJ} / \mathrm{kg}$. This behavior shows the efficiency benefits of the component when its mass increases. However, the maximum value of $24 \mathrm{~kJ} / \mathrm{kg}$ is obtained with a similar configuration to the one shown in section IV.A.1, with thick aluminum, low GFRP thickness, and a rectangular cell with an intermediate size.

\section{IV.B.2. SEA - $P_{\text {peak }}$ optimization}

The second multi-objective optimization is the one that confronts $S E A$ and $P_{\text {peak }}$ (fig. 10). Results are significantly non-linear, in contrast with the mass $-E_{\mathrm{a}}$ Pareto frontier, mainly caused by the variation of the aluminum's thickness. As the tube thickens, the increase on the peak force is greater than the increase obtained for the SEA objective function due to the impact simulation's characteristics. Again, the cell size decreases to obtain higher $S E A$ - and $P_{\text {peak }}$ - values, but it never surpasses the 11.5 millimeter threshold, as it would harm both metrics. The thickness of the aluminum increases to its upper boundary, but the GFRP stays thin throughout the frontier, 


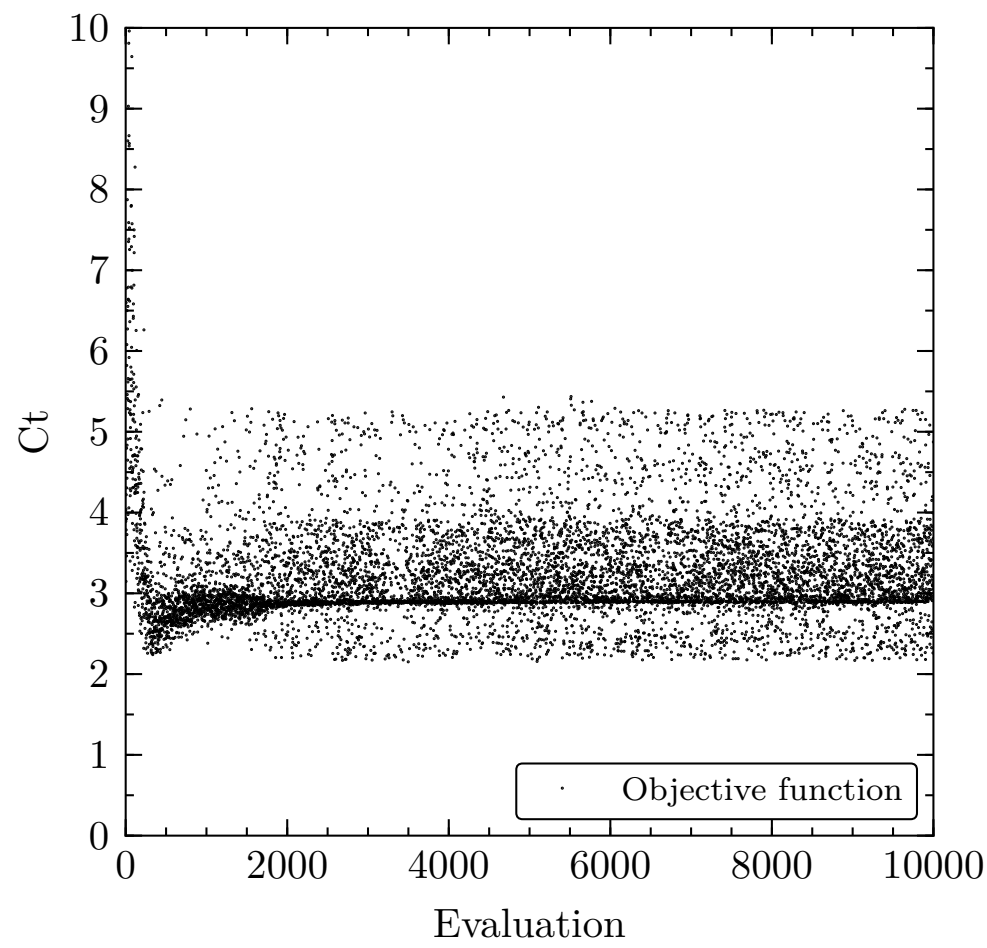

Figure 8: Evolution of the cost function during the single-objective optimization for the SC4 case.

showing the greater contribution of the aluminum to high specific energy absorption values. This is caused by the differences between the collapse mechanisms of both materials, since the ductile nature of the metal allows the formation of folds and, therefore, a higher energy absorption without increasing the initial peak force. Lastly, the cell shapes that yield the highest SEA are those close to a rectangle, as it could also be seen in the mass - $E_{\mathrm{a}}$ front (table 11) and the single-objective $S E A$ optimization, since other shapes introduce more GFRP in the component and reduce the mass of the foam.

\section{IV.B.3. SEA - $C_{t}$ optimization}

The last optimization confronts the SEA and the component's cost. Four Pareto fronts are obtained, since the four different cost weights combinations from table 5 were used. The graphs from fig. 11 show this four frontiers, with a noticeably similar shape, but with a certain offset of the frontier using the SC2 weights. This happens due to the small (but reasonable) reduction of the weights used in the SC2 cost function. The combination named SC1, where $\lambda_{\mathrm{a}}=\lambda_{\mathrm{g}}=\lambda_{\mathrm{f}}=1.0$ has a special interest, since $C t=m$, and the $S E A-C_{t}$ front translates into a $S E A-m$ frontier. As seen in table 13 and fig. 12, the cell size tends to the maximum allowed in order to obtain a higher $S E A$, as it introduces the least GFRP on the model. The same behavior can be appreciated for the aluminum's thickness which reaches the maximum for components with over $4 \mathrm{~kg}$. However, the honeycomb laminates stay in the lower thickness boundary value throughout the whole frontier, as 


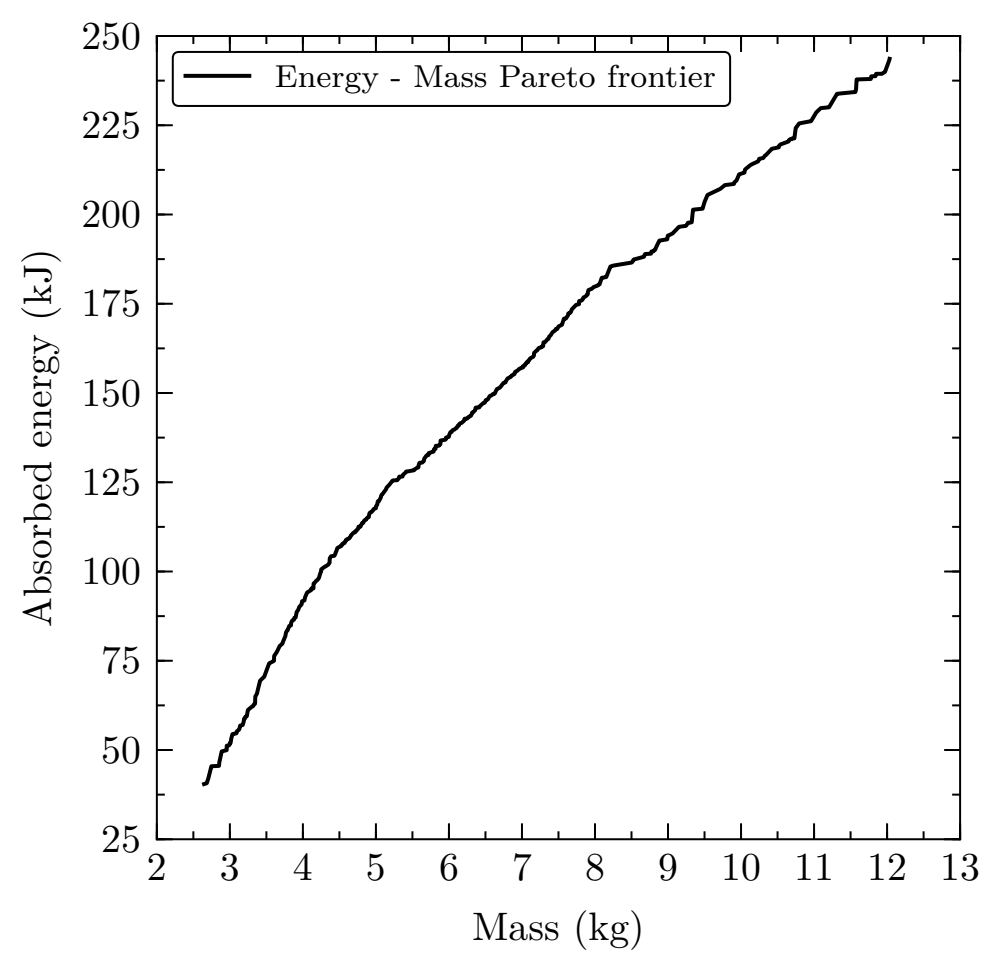

Figure 9: Mass - $E_{\mathrm{a}}$ Pareto front.

the GFRP's density is higher than that of the foam. The cell shape starts with the regular hexagon, tending towards the rectangular shape and even slightly surpassing this threshold for the highest $S E A$ values, as expected after the results obtained in other Pareto fronts.

\section{Conclusions}

This research proposes a crashworthiness optimization of a vertical strut used for energy absorption of aircraft structures. A standard aluminum tube filled with a GFRP honeycomb structure, whose cells are also filled with foam, is crushed under impact conditions. The component is optimized by varying the aluminum and GFRP thicknesses, as well as the honeycomb's cell size and shape.

Five objective functions are considered for single- and multi-objective optimization: the mass of the model, the energy absorbed during the crushing, maximum force, specific energy absorption and total cost of the component. Results show that the use of a foam filling enhances the specific energy absorption response by $28 \%$ when unconstrained single-objective optimization is performed, thus justifying its usage. Furthermore, the baseline model is also bettered by ultimately increasing $22 \%$ the specific energy absorption value when an optimization with a peak force constraint of the baseline model peak force is carried out.

The cost of the component is also optimized with $P_{\text {peak }}$ and $S E A$ constraints. Four different cost 


\begin{tabular}{|c|c|c|c|c|c|c|}
\hline \multicolumn{4}{|c|}{ Design variables $(\mathrm{mm})$} & \multicolumn{2}{|c|}{ Objective functions } & \multirow{2}{*}{$\frac{\text { Indicator }}{S E A(\mathrm{~kJ} / \mathrm{kg})}$} \\
\hline L1 & $\mathrm{T} 1$ & $\mathrm{~T} 2$ & $\mathrm{~S}$ & m (kg) & $E_{\mathrm{a}}(\mathrm{kJ})$ & \\
\hline 17.81 & 1.08 & 1.17 & 0.10 & 2.65 & 40.46 & 15.29 \\
\hline 15.24 & 1.97 & 1.02 & 0.31 & 3.60 & 74.96 & 20.80 \\
\hline 16.37 & 2.49 & 1.02 & 0.54 & 4.47 & 106.54 & 23.83 \\
\hline 11.68 & 2.49 & 1.23 & 0.47 & 5.15 & 123.55 & 24.00 \\
\hline 9.17 & 2.49 & 1.80 & 0.31 & 6.65 & 151.07 & 22.70 \\
\hline 9.17 & 2.49 & 2.82 & 0.16 & 8.26 & 185.71 & 22.50 \\
\hline 9.57 & 2.49 & 2.69 & 0.62 & 10.05 & 211.73 & 21.08 \\
\hline 9.16 & 2.49 & 2.89 & 0.73 & 12.03 & 243.61 & 20.24 \\
\hline
\end{tabular}

Table 11: Points from mass $-E_{\mathrm{a}}$ Pareto front.

\begin{tabular}{ccccccc}
\hline \multicolumn{3}{c}{ Design variables $(\mathrm{mm})$} & & \multicolumn{2}{c}{ Objective functions } \\
\cline { 1 - 1 } $\mathrm{L} 1$ & $\mathrm{~T} 1$ & $\mathrm{~T} 2$ & $\mathrm{~S}$ & & SEA $(\mathrm{kJ} / \mathrm{kg})$ & $P_{\text {peak }}(\mathrm{kN})$ \\
\hline 17.30 & 1.48 & 1.07 & 0.16 & & 17.56 & 221.19 \\
16.77 & 1.61 & 1.02 & 0.27 & & 18.46 & 240.39 \\
15.76 & 1.92 & 1.02 & 0.16 & & 20.05 & 277.67 \\
16.80 & 2.15 & 1.07 & 0.39 & & 21.85 & 310.26 \\
14.73 & 2.49 & 1.02 & 0.07 & & 22.41 & 343.19 \\
15.62 & 2.48 & 1.02 & 0.50 & & 23.71 & 383.25 \\
11.72 & 2.47 & 1.28 & 0.48 & 24.05 & 532.25 \\
\hline
\end{tabular}

Table 12: Points from $S E A-P_{\text {peak }}$ Pareto front.

functions are used, where results reduce the cost and $P_{\text {peak }}$ up to $40 \%$, while maintaining the same SEA as the baseline model.

As for the multi-objective optimization, three different configurations are proposed, with their respective Pareto fronts: energy absorbed - mass, SEA - peak force, and SEA - cost. The energy absorbed - mass frontier shows a pseudo-linear tendency, with high efficiency in its the mid-range, obtaining $S E A$ values of up to $24 \mathrm{~kJ} / \mathrm{kg}$ for five- $\mathrm{kg}$ components. It is significant the variation of the cell shape, gradually swifting from a regular hexagon to the hourglass shape. The SEA - peak force Pareto front is also greatly affected by the cell size and shape, obtaining the highest values of $S E A$ - over $23 \mathrm{~kJ} / \mathrm{kg}$ - for rectangular honeycomb cells with an edge length between 16 and 11 millimeters.

Lastly, four frontiers are also obtained confronting SEA and the component's cost, originated from the four different weights given to the cost function. All four of them are similar in shape, 


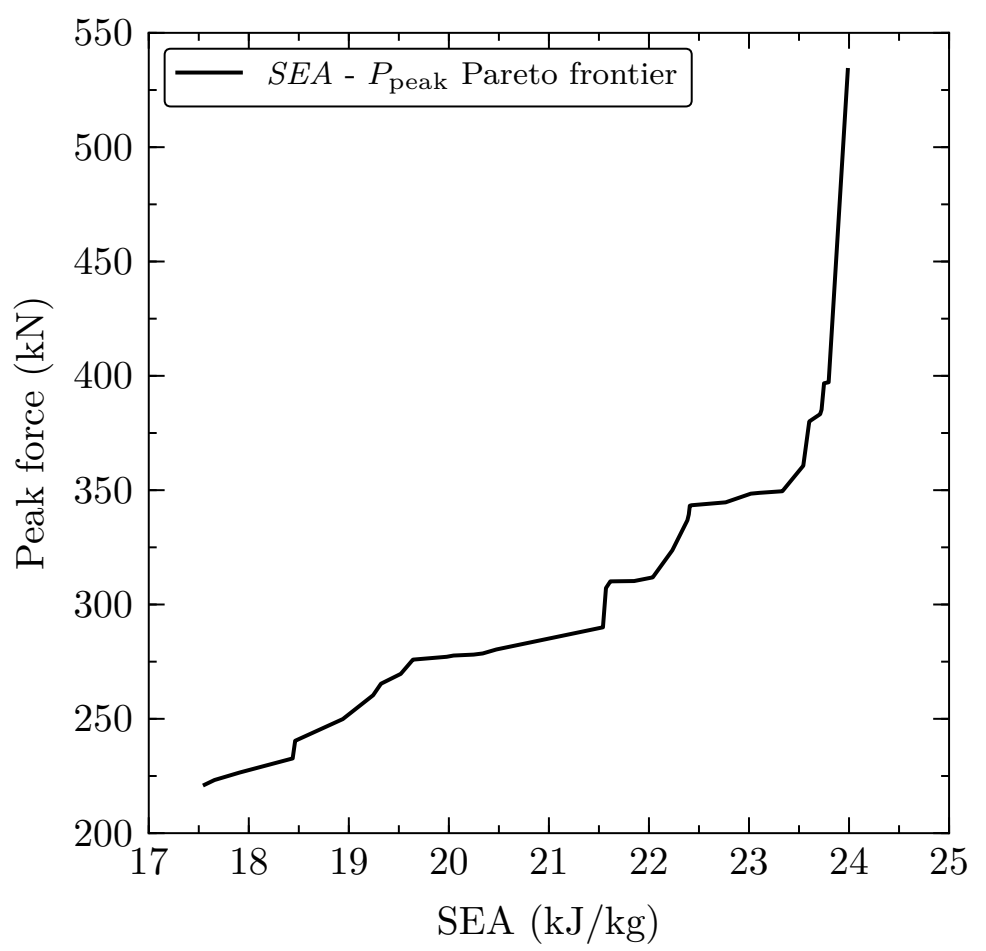

Figure 10: $S E A$ - $P_{\text {peak }}$ Pareto front.

with a slight offset between the configuration with the lowest cost weights and the others. From the data obtained concerning the variables' evolution, steady GFRP thickness and cell size are perceived. However, as the SEA increased, the cell shape tended to the rectangular shape, whereas the aluminum's thickness reached the highest value allowed.

The results from both the single- and multi-objective optimization show the great improvement obtained from filling the honeycomb cells with foam, as well as the optimum configurations attending to different criteria. It is also noted that for the components with the highest SEA obtained, the cell shape is that close to a rectangle, the cell size and aluminum thickness hover around the

\begin{tabular}{ccccllll}
\hline \multicolumn{3}{c}{ Design variables $(\mathrm{mm})$} & & \multicolumn{3}{c}{ Objective functions } \\
\cline { 1 - 3 } \cline { 6 - 7 } $\mathrm{L} 1$ & $\mathrm{~T} 1$ & $\mathrm{~T} 2$ & $\mathrm{~S}$ & & SEA $(\mathrm{kJ} / \mathrm{kg})$ & $C_{t}$ \\
\hline 16.26 & 1.01 & 1.05 & $0.01^{(* 1)}$ & 14.24 & 2.47 \\
17.48 & 1.42 & 1.05 & 0.16 & 17.24 & 2.88 \\
17.91 & 1.87 & 1.07 & $0.31^{(* 2)}$ & 19.67 & 3.34 \\
17.91 & 2.24 & 1.05 & 0.36 & 22.01 & 3.66 \\
17.91 & 2.49 & 1.06 & $0.41^{(* 3)}$ & 23.12 & 4.07 \\
17.51 & 2.50 & 1.05 & $0.55^{(* 4)}$ & 23.91 & 4.44 \\
\hline
\end{tabular}

Table 13: Points from $S E A-C_{t}$ Pareto front for SC1. Model with an * depicted in figs. 13a to $13 \mathrm{~d}$. 


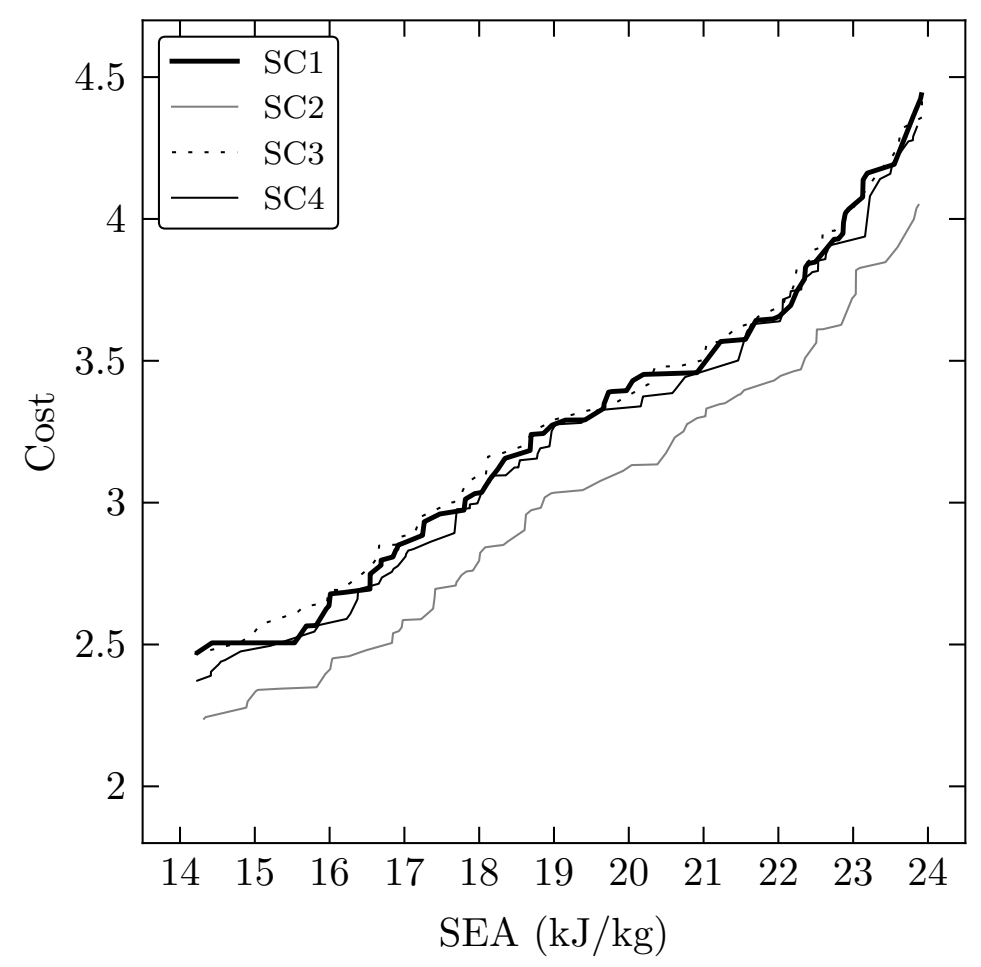

Figure 11: $S E A-C_{t}$ Pareto front.

maximum, and the honeycomb thickness tends to the lowest value allowed.

The cell size, cell shape and cell thickness tendencies reduce the weight added by the GFRP and increase the foam in the model, while still constraining the foam's collapse. Furthermore, the aluminum's thickness tends to the maximum, since the penalty added by the weight to the $S E A$ function is less significant than the increase of the energy absorbed due to its ductile collapse mechanism.

\section{Acknowledgements}

The research leading to these results has received funding from the Spanish Goverment (Ministerio de Economía y Competitividad) under grant agreement DPI2013-41893-R. The authors fully acknowledge the support received. 


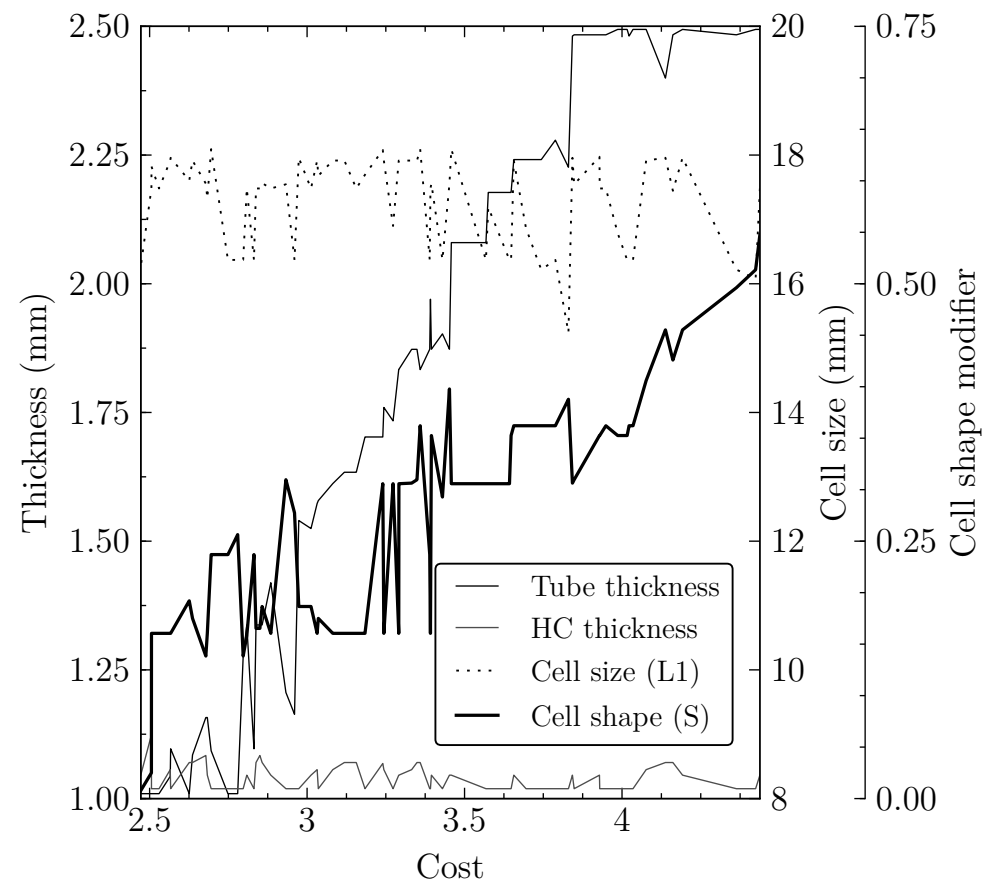

Figure 12: Variables' evolution for SC1 in the $S E A-C_{t}$ Pareto frontier.

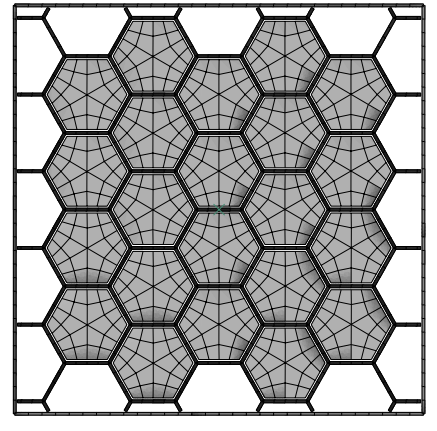

(a) Model (*1) from table 13 .

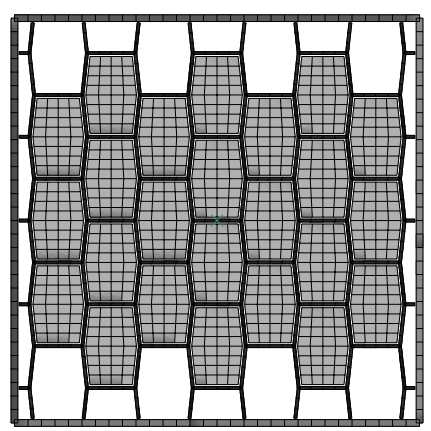

(c) Model (*3) from table 13 .

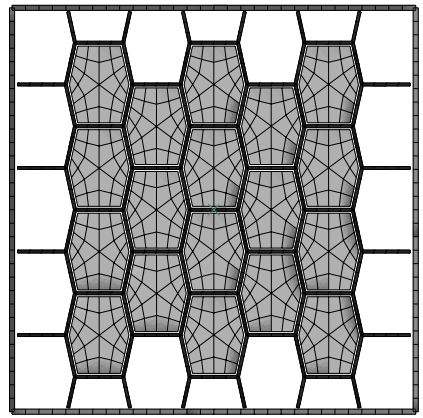

(b) Model (*2) from table 13.

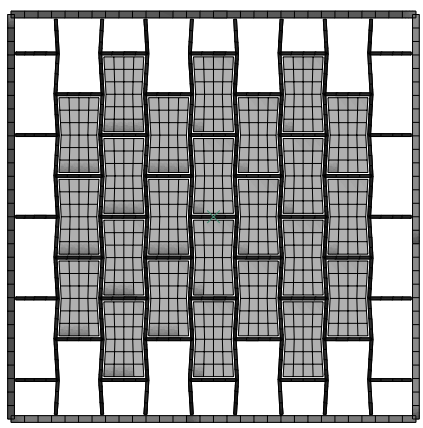

(d) Model (*4) from table 13.

Figure 13: component configuration for some points from the $S E A-C_{t}$ Pareto frontier from table 13 . 


\section{References}

1 De Florio, F., Airworthiness: An Introduction to Aircraft Certification, Oxford, 2006.

2 Heimbs, S., "Energy absorption in aircraft structures," International Workshop on Hydraulic Equipment and Support Systems for Mining.

3 Fasanella, E. L., Jackson, K. E., Lyle, K. H., Sparks, C. E., and Sareen, A. K., "Multi-terrain impact tests and simulations of an energy absorbing fuselage section," Journal of the American Helicopter Society, vol. 52, no. 2.

4 Heimbs, S., Mehrens, T., Middendorf, P., Maier, M., and Schumacher, A., "Numerical Determination of the Nonlinear Effective Mechanical Properties of Folded Core Structures for Aircraft Sandwich Panels," 6th European LS-DYNA Users' Conference, pp. 1-14.

5 Meng, F. X., Zhou, Q., and Yang, J. L., "Improvement of crashworthiness behaviour for simplified structural models of aircraft fuselage," International Journal of Crashworthiness, vol. 14, no. 1, (2009), pp. 83-97.

6 Wiggenraad, J. F. M., Michielsen, A., Santoro, D., Le Page, F., Kindervater, C., Beltran, F., and Alkhalil, M., "Finite element methodologies development to simulate the behaviour of composite fuselage structure and correlation with drop test," Air and Space Eur 33, pp. 228233.

7 Woodson, M. B., Johnson, E. R., and Haftka, R. T., "Optimal design of composite fuselage frames for crashworthiness," International Journal of Crashworthiness.

8 Lyle, K., Stockwell, A., and Hardy, R., "Application of probability methods to assess airframe crash modeling uncertainty," Journal of Aircraft, vol. 44, no. 5, (2007), pp. 1568-1573.

9 Kumakura, I., Minegishi, M., and Iwasaki, K., "Impact simulation of simplified structural models of aircraft fuselage," 2000 World Aviation Conference.

10 Shoji, H., Minegishi, M., and Aoki, T., "Impact characteristics estimation of channel section short column under axial impact load," Structural Dynamics and Materials Conference, vol. 4, (2007), pp. 3967-3976.

11 Alexander, J. M., "An approximate analysis of the collapse of thin cylindrical shells under axial loading," Quarterly Journal of Mechanics and Applied Mathematics, vol. 13, no. 1, (1960), pp. $10-15$.

12 Wierzbicki, T. and Abramowicz, W., "On the crushing mechanics of thin-walled structures," Journal of Applied Mechanics, Transactions ASME, vol. 50, no. 4 a, (1983), pp. 727-734. 
13 Abramowicz, W. and Jones, N., "Transition from initial global bending to progressive buckling of tubes loaded statically and dynamically," International Journal of Impact Engineering, vol. 19, no. 5-6, (1997), pp. 415-437.

14 Ren, Y. and Xiang, J., “A comparative study of the crashworthiness of civil aircraft with different strut configurations," International Journal of Crashworthiness, vol. 15, no. 3, (2010), pp. $321-330$.

15 Ren, Y. and Xiang, J., "The crashworthiness of civil aircraft using different quadrangular tubes as cabin-floor struts," International Journal of Crashworthiness, vol. 16, no. 3, (2011), pp. 253-262.

16 Jia, X., Chen, G., Yu, Y., Li, G., Zhu, J., Luo, X., Duan, C., Yang, X., and Hui, D., “Effect of geometric factor, winding angle and pre-crack angle on quasi-static crushing behavior of filament wound cfrp cylinder," Composites Part B: Engineering, vol. 45, no. 1, (2013), pp. 1336-1343.

17 Zou, T., Mou, H., and Feng, Z., "Research on Effects of Oblique Struts on Crashworthiness of Composite Fuselage Sections," Journal of Aircraft, vol. 49, no. 6, (2012), pp. 2059-2063.

18 Paz, J., Díaz, J., Romera, L., and Costas, M., "Crushing analysis and multi-objective crashworthiness optimization of GFRP honeycomb-filled energy absorption devices," Finite Elements in Analysis and Design, vol. 91, (2014), pp. 30-39.

19 Miller, W., Smith, C. W., and Evans, K. E., "Honeycomb cores with enhanced buckling strength," Composite Structures, vol. 93, no. 3, (2011), pp. 1072-1077.

20 Yin, H., Wen, G., Hou, S., and Chen, K., "Crushing analysis and multiobjective crashworthiness optimization of honeycomb-filled single and bitubular polygonal tubes," Materials and Design, vol. 32, no. 8-9, (2011), pp. 4449-4460.

21 Schultz, J., Griese, D., Ju, J., Shankar, P., Summers, J., and Thompson, L., "Design of honeycomb mesostructures for crushing energy absorption," Journal of Mechanical Design, Transactions of the ASME, vol. 134, no. 7.

22 Hanssen, A., Langseth, M., and Hopperstad, O., "Static and dynamic crushing of square aluminum extrusions with aluminum foam filler," International Journal of Impact Engineering, vol. 24, no. 4, (2000), pp. 347-383.

23 Hanssen, A., Langseth, M., and Hopperstad, O., "Optimum design for energy absorption of square aluminum columns with aluminum foam filler," International Journal of Mechanical Sciences, vol. 43, no. 1, (2001), pp. 153-176. 
24 Costas, M., Morin, D., Langseth, M., Romera, L., and Díaz, J., "Axial crushing of aluminum extrusions filled with PET foam and gfrp. an experimental investigation," Thin-Walled Structures, vol. 99, (2016), pp. $45-57$.

25 Cid Montoya, M., Costas, M., Díaz, J., Romera, L., and Hernández, S., "A multi-objective reliability-based optimization of the crashworthiness of a metallic-GFRP impact absorber using hybrid approximations," Structural and Multidisciplinary Optimization, vol. 52, no. 4, (2015), pp. 827-843.

26 Cook, G. R. and Johson, W. H., "A constitutive model and data for metals subjected to large strains, high strain rates and high temperatures," Proceedings of Seventh International Symposium on Ballistics.

27 Børvik, T., Hopperstad, O., Berstad, T., and Langseth, M., "A computational model of viscoplasticity and ductile damage for impact and penetration," European Journal of Mechanics, A/Solids, vol. 20, no. 5, (2001), pp. 685-712.

28 Børvik, T., Hopperstad, O., and Pedersen, K., "Quasi-brittle fracture during structural impact of AA7075-T651 aluminium plates," International Journal of Impact Engineering, vol. 37, no. 5, (2010), pp. 537-551.

29 BASF, “Ultramid (r) A3WG10 BK00564 Polyamide 66. Product information sheet,”, 2012.

30 Paz, J., Díaz, J., Romera, L., and Costas, M., "Size and shape optimization of aluminum tubes with GFRP honeycomb reinforcements for crashworthy aircraft structures," Composite Structures, vol. 133, (2015), pp. 499-507.

31 Deshpande, V. and Fleck, N., "Isotropic constitutive models for metallic foams," Journal of the Mechanics and Physics of Solids, vol. 48, no. 6, (2000), pp. 1253-1283.

32 McKay, M., Beckman, R., and Conover, W., "A comparison of three methods for selecting values of input variables in the analysis of output from a computer code," Technometrics, vol. 21, no. 2, (1979), pp. 239-245.

33 Eglajs, V. and Audre, P., "New approach to the design of multifactor experiments," Problems of Dynamics and Strengths, pp. 104-107.

34 Nealen, A., "A short-as-possible introduction to the least squares, weighted least squares, and moving least squares methods for scattered data approximation and interpolation." Technical report, Discrete Geometric Modeling Group, Technishe Universität, Berlin, Germany.

35 Zhao, L., Choi, K., and Lee, I., "Metamodeling method using dynamic kriging for design optimization," AIAA Journal, vol. 49. 
36 Eddy, J. E. and Lewis, K., "Effective generation of pareto sets using genetic programming," Proceedings of ASME Design Engineering Technical Conference.

37 ABAQUS 6.14 Documentation, Dassault Systèmes, 2014.

38 Adams, B., Bauman, L., Bohnhoff, W., Dalbey, K., Ebeida, M., Eddy, J., Eldred, M., Hough, P., Hu, K., Jakeman, J., Swiler, L., and Vigil, D., DAKOTA, A Multilevel Parallel Object-Oriented Framework for Design Optimization, Parameter Estimation, Uncertainty Quantification, and Sensitivity Analysis: Version 6.1.0 User's Manual, Sandia National Laboratories, July 2014. Updated November 2014. 